\title{
Identification of testis-relevant genes using in silico analysis from testis ESTs and CDNA microarray in the black tiger shrimp (Penaeus monodon)
}

Thidathip Wongsurawat ${ }^{1 \dagger}$, Rungnapa Leelatanawit ${ }^{1,2+}$, Natechanok Thamniemdee', Umaporn Uawisetwathana', Nitsara Karoonuthaisiri ${ }^{*}$, Piamsak Menasveta ${ }^{3,4}$, Sirawut Klinbunga ${ }^{1,3}$

\begin{abstract}
Background: Poor reproductive maturation of the black tiger shrimp (Penaeus monodon) in captivity is one of the serious threats to sustainability of the shrimp farming industry. Understanding molecular mechanisms governing reproductive maturation processes requires the fundamental knowledge of integrated expression profiles in gonads of this economically important species. In $P$. monodon, a non-model species for which the genome sequence is not available, expressed sequence tag (EST) and cDNA microarray analyses can help reveal important transcripts relevant to reproduction and facilitate functional characterization of transcripts with important roles in male reproductive development and maturation.
\end{abstract}

Results: In this study, a conventional testis EST library was exploited to reveal novel transcripts. A total of 4,803 ESTs were unidirectionally sequenced and analyzed in silico using a customizable data analysis package, ESTplus. After sequence assembly, 2,702 unique sequences comprised of 424 contigs and 2,278 singletons were identified; of these, 1,133 sequences are homologous to genes with known functions. The sequences were further characterized according to gene ontology categories (41\% biological process, $24 \%$ molecular function, 35\% cellular component). Through comparison with EST libraries of other tissues of $P$. monodon, 1,579 transcripts found only in the testis cDNA library were identified. A total of 621 ESTs have not been identified in penaeid shrimp. Furthermore, cDNA microarray analysis revealed several ESTs homologous to testis-relevant genes were more preferentially expressed in testis than in ovary. Representatives of these transcripts, homologs of saposin (PmSap) and Dmc1 (PmDmc1), were further characterized by RACE-PCR. The more abundant expression levels in testis than ovary of PmSap and PmDmcl were verified by quantitative real-time PCR in juveniles and wild broodstock of $P$. monodon.

Conclusions: Without a genome sequence, a combination of EST analysis and high-throughput cDNA microarray technology can be a useful integrated tool as an initial step towards the identification of transcripts with important biological functions. Identification and expression analysis of saposin and Dmc1 homologs demonstrate the power of these methods for characterizing functionally important genes in P. monodon.

\footnotetext{
* Correspondence: nitsara.kar@biotec.or.th

† Contributed equally

${ }^{1}$ National Center for Genetic Engineering and Biotechnology (BIOTEC), National Science and Technology Development Agency, Klong 1, Klong Luang, Pathumthani 12120, Thailand

Full list of author information is available at the end of the article
} 


\section{Background}

The black tiger shrimp (Penaeus monodon) is an aquatic animal of central importance as it brings an annual income of over one billion USD in Thailand [1]. However, domestication of the black tiger shrimp (Penaeus monodon) is impeded by poor reproductive maturation of both male and female brooders in captivity. Ovarian development of penaeid shrimp is induced by a unilateral eyestalk ablation technique; however, the technique does not have the same effect in male reproductive maturation [2]. No molecular markers pinpointing the maturation stage of testis or sperm quality in penaeid shrimp are currently known. Domesticated male P. monodon yields lower fertilization rates of zygotes and lower survival rates of offspring than wild male P. monodon [3]. However, the role of genes implicated in the regulation of spermatogenesis and their patterns of expression in penaeid shrimp are still poorly understood.

To gain insight on the molecular mechanisms governing the male reproduction process of this important species, EST libraries from P. monodon broodstock testis were previously constructed for gene discovery [4,5]. A testis-specific transcript, PMTST1 (P. monodon testisspecific transcript 1 ), was identified, and expression levels of 51 additional putative testis-specific genes in cultured and wild $P$. monodon were examined by reverse-transcription (RT)-PCR, semiquantitative RTPCR, and real-time RT-PCR [5]. Nevertheless, more exhaustive gene discovery is needed to unravel testisrelevant genes and their possible functions.

In this study, a total of 4,803 ESTs from the testis library were sequenced and analyzed in silico using a customizable data analysis package, ESTplus [6]. Many transcripts known to be relevant to testicular development in other organisms were identified. A total of 1,076 of these testis EST sequences were included in the construction of a new microarray. Gene expression profiles of testis were simultaneously compared to those of ovary in both juveniles and broodstock. Among transcripts with differential expression levels, saposin and Dmc1 homologs were further examined by quantitative real-time PCR. Furthermore, full-length sequences of saposin and Dmc1 cDNAs were obtained by RACE-PCR.

\section{Results and Discussion}

\section{Characteristics and functional annotation of testis ESTs of} P. monodon

Previously, we constructed suppression subtractive hybridization ( $\mathrm{SSH}$ ) libraries comparing cDNA in testis of wild P. monodon broodstock to juveniles. A total of 365 clones were sequenced from these libraries [4]. In addition, we established a high quality conventional cDNA library from testis of wild P. monodon broodstock and preliminarily sequenced 896 clones [5]. In this study, additional ESTs were sequenced from the conventional cDNA library and a total of 4,803 high quality EST sequences were obtained (Figure 1A). Results of the in silico analysis are summarized in Figure 2. From assembling the testis EST sequences, 2,702 unique sequences comprising of 424 contigs and 2,278 singletons with an average size of $1,130 \mathrm{bp}$ and $584 \mathrm{bp}$, respectively, were found. When compared with the NCBI nucleotide collection ( $\mathrm{nr} / \mathrm{nt}$ ) database using BlastN, 1,181 sequences of the 2,702 unique sequences were found to be homologs of previously reported sequences. Similarly, when the unique EST sequences were compared with the NCBI non-redundant protein sequence database using BlastX, 1,147 (42\%) sequences were homologs of previously reported sequences, whereas the remainder (1,555 sequences, 58\%) were unknown (novel) transcripts. Matched sequences $(1,147)$ from the BlastX analysis were further categorized by Blast2GO for their potential functions. 1,133 (99\%) of these sequences were similar to genes with putative functions (Figure 2A).

$E$-values of most sequences ranged between $1 \mathrm{e}-30$ to $1 \mathrm{e}-10$ (396 sequences accounting for $34 \%$ of overall contigs, Figure $3 \mathrm{C}$ ). The most frequently matched transcripts found were Arthropoda (753 sequences, 66\%) at the phylum level and the red flour beetle Tribolium castaneum (90 sequences) at the species level (Table 1). This could be due to the limited availability of P. monodon sequence data in comparison to that of $T$. castaneum whose genome was completely sequenced and published in 2008 [7].

The 2,702 unique sequences were searched using BlastN against the P. monodon EST data (PmDB: http:// pmonodon.biotec.or.th) excluding previously identified testis EST libraries (Figure 2B). A total of 1,579 sequences did not match ESTs from other tissues of $P$. monodon making them potential testis-specific transcripts or rare transcripts in other shrimp tissues. Examples of genes in this group relevant to testicular development are phospholipase A2, mago nashi proliferation-associated protein, actin-depolymerizing factor and profilin. Phospholipase A2 is required for the acrosome reaction (AR), a special exocytotic process promoted by signal transduction pathways, and capacitation, a process for maturation of spermatozoa [8,9]. Protein mago nashi originally identified in Drosophila is essential for germplasm assembly [10]. Actin polymerization is important for a wide range of cellular functions and properties, including cell division, cell motility, cell polarity and cellcell contacts. Profilins are widely expressed small actinbinding proteins which are functionally involved in the regulation of actin dynamics $[11,12]$. On the other hand, 


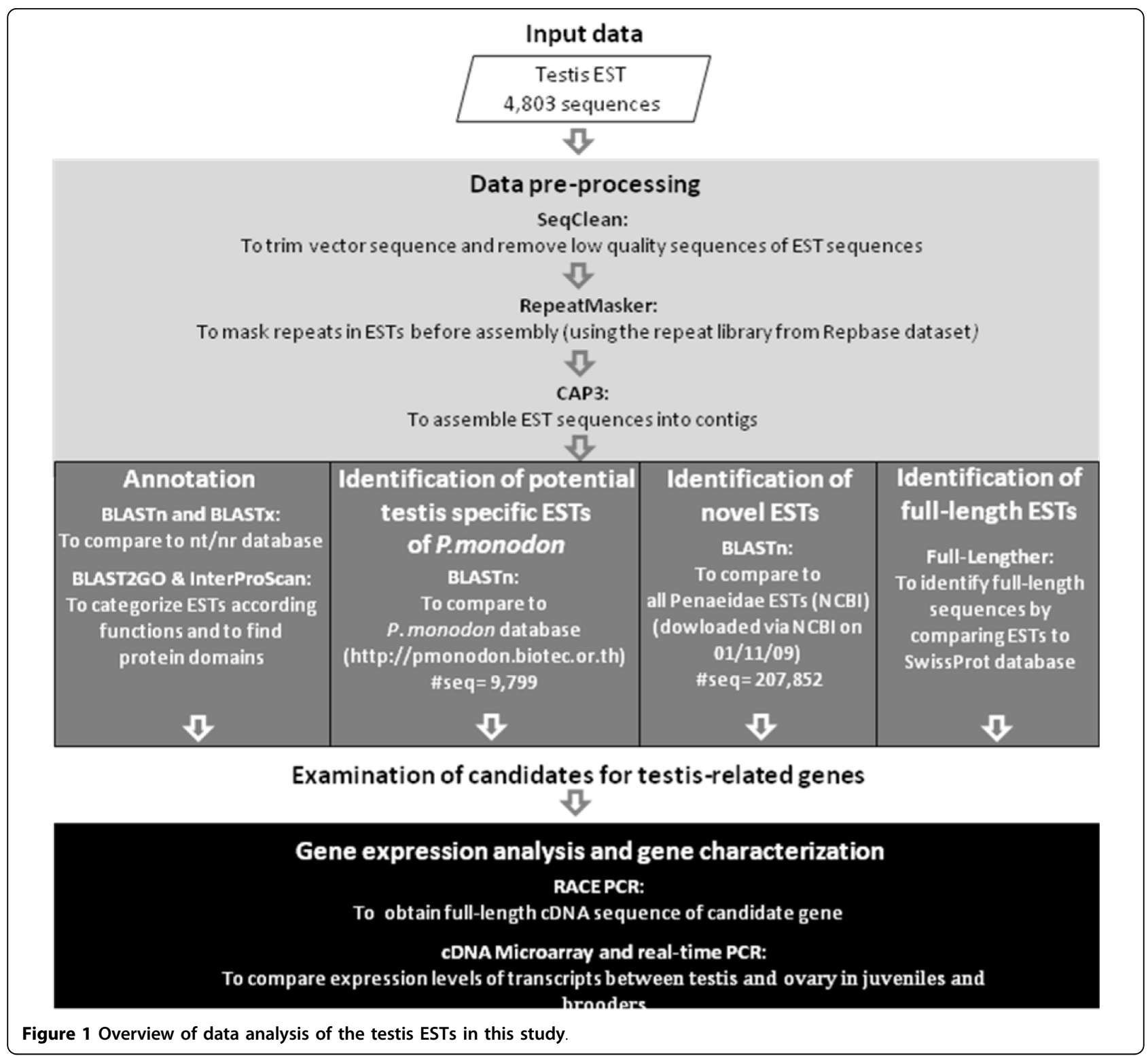

cofilin/actin-depolymerizing protein is an important factor in spermatogenesis which disassembles actin filaments when unphosphorylated [13].

To reveal novel transcripts which are not found in other Penaeidae ESTs, the testis ESTs from this study were also compared to Penaeid ESTs (207,852 sequences, using a keyword of "Penaeidae") from the NCBI database (Figure 2C). A total of 2,081 (77\%) sequences were homologous to those from the NCBI's penaeid shrimp database. 621 newly identified transcripts (23\%) were found, 475 of which (18\%) have not been reported in the PmDB database.

Most of the obtained EST sequences ranged from 201$1,100 \mathrm{bp}$ in length (Figure 3A). Apart from a large number of singletons (2,278 unique sequences, $84 \%$ of discovered sequences), most of the contigs (187 contigs, 7\%) were assembled from two ESTs and only 100 contigs (4\%) were deduced from greater than five ESTs. Only three contigs; cytochrome C oxidase subunit 1 (COI), elongation factor 1alpha $(E F-1 \alpha)$, and cell division cycle $2(c d c 2)$ were assembled from over 50 sequences (Figure $3 \mathrm{~B}$ ). EF-1 $\alpha$ functions in protein synthesis by promoting the binding of aminoacyl tRNA to the $80 \mathrm{~S}$ ribosome, and it is one of the most abundant soluble proteins in eukaryotes [14]. Mitochondrial COI has been found to be more highly expressed in well differentiated cells with high activity than in moderately and poorly differentiated cells $[15,16]$. $\mathrm{Cdc} 2$ is the key regulator of the eukaryotic cell cycle, and its activity is controlled by interaction with other proteins such as cyclin A and cyclin B1 [17]. Mitotic cyclins and 


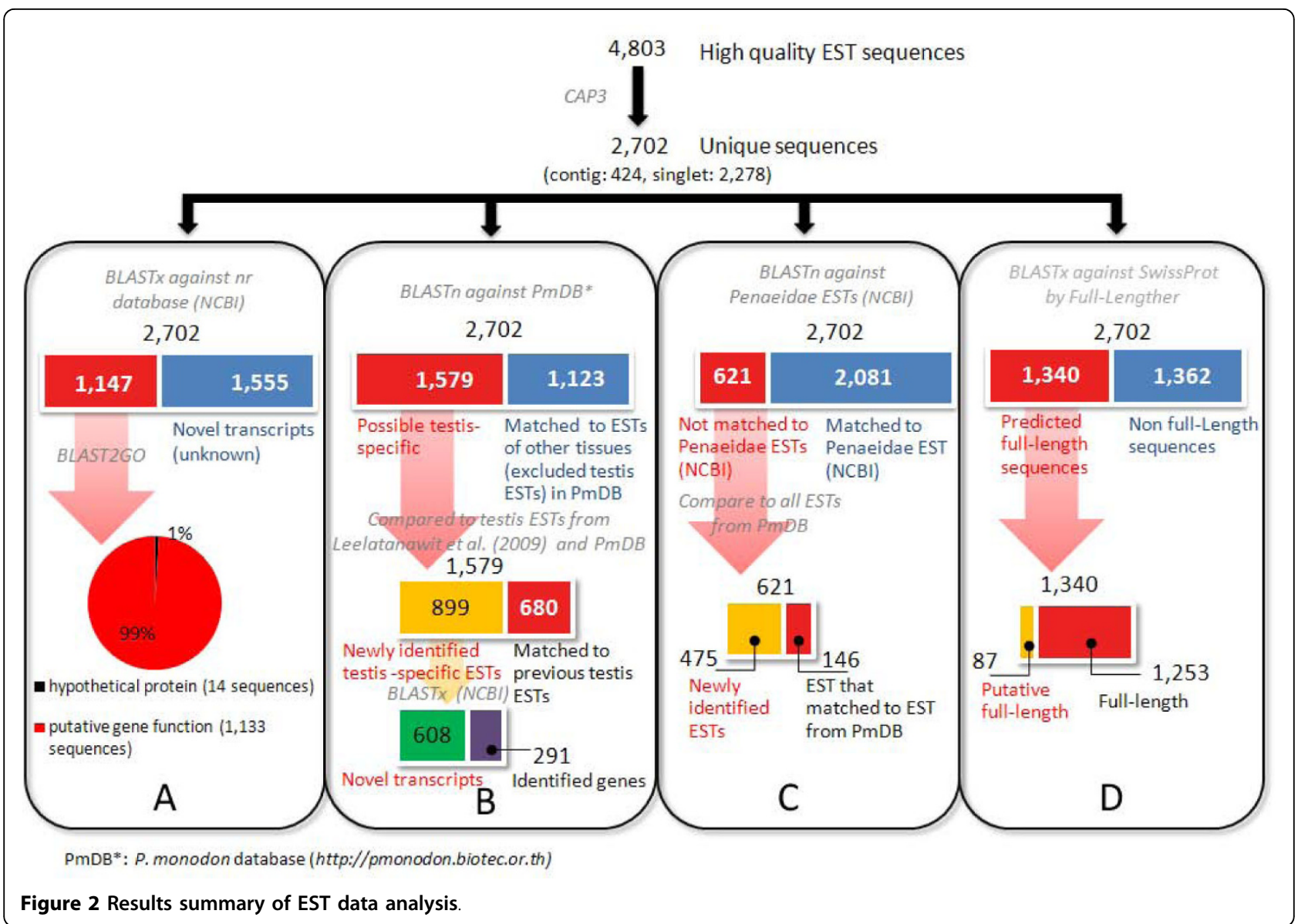

cdc2 are involved in capacitation and/or acrosome reaction of sperm [18]. During the meiotic cell cycle, the $\mathrm{G} 2 / \mathrm{M}$ phase transition is controlled by the maturation promoting factor (MPF), a complex of cdc2 (cdk1) and cyclin B1 [19]. High redundancies of these transcripts in the ESTs are consistent with their essential cellular functions during spermatogenesis and testicular development.

The assembled EST sequences with similarity to the $\mathrm{nr} / \mathrm{nt}$ database (1,147 from 2,702 sequences; Figure 2A) were further categorized according to Gene Ontology (Figure 4$)$. The majority of annotated ESTs (41\% of 1,147 sequences) were placed in the Gene Ontology functional category of "biological processes". The remaining annotated ESTs were placed in the "cellular components" (35\% of 1,147 sequences) and "molecular function" (24\% of 1,147 sequences) categories. Compared to the EST sequences from the P. monodon EST database, the distribution for the three main categories was similar $(42 \%, 31 \%$, and $27 \%$ for biological processes, cellular components and molecular function, respectively).

In the biological process category, ESTs involved in the cellular process were predominant (30\% of examined
ESTs), followed by those involved in the metabolic process (25\% of examined ESTs). In the cellular component category, EST functionally involved in the cell (39\% of examined ESTs) predominated followed by those functionally displayed in the organelles $(30 \%$ of examined ESTs) and macromolecular complex (21\% of examined ESTs). In the molecular function category, ESTs displaying binding function (43\% of examined ESTs) predominated followed by those displaying catalytic activity $(28 \%$ of examined ESTs).

The reproduction group, including mago-nashi proliferation-associated protein, ubiquitin-conjugating enzyme E2, and small ubiquitin-related modifier precursor (SUMO), contributes $\sim 2 \%$ of the total number of contigs. This discovery rate is comparable to that identified from the conventional ovarian cDNA library of $P$. monodon [20].

The transcripts found in the reproduction group exhibit relevant functions to male reproduction. For instance, SUMO plays an important role in diverse reproductive functions such as spermatogenesis and modulation of steroid receptor activity [21]. In the sumoylation pathway, SUMO is transferred to lysine 


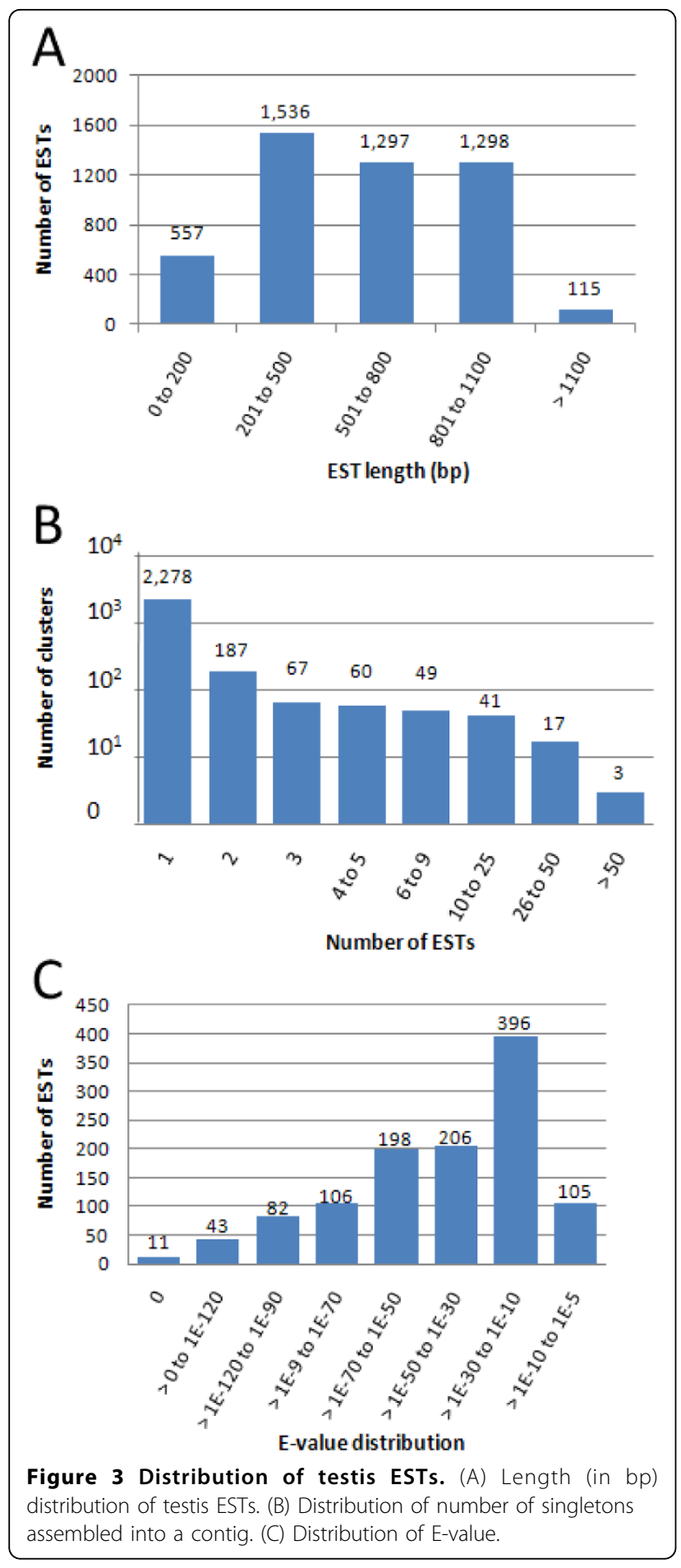

residues of the protein substrates through the thioester cascade of ubiquitin activating enzyme $\mathrm{E} 1$ and ubiquitin conjugating enzyme E2 (UBE2), and SUMO ligase E3 [22]. In the kuruma shrimp Marsupenaeus japonicus, UBE2 was expressed at a higher level in testis than in ovary. The expression at stage I (GSI $=0.33 \pm 0.004$, $N=5$ ) was significantly lower than that of stage II
(GSI $=0.45 \pm 0.12, N=5$ ) but comparable to that of stage III (GSI $=0.57 \pm 0.006, N=5$ ) of testis [23]. The analysis of baseline information acquired by this study addresses the paucity of data and provides a better understanding of reproductive maturation in male P. monodon.

\section{Differential Gene Expression Patterns by CDNA Microarrays}

To address the functional involvement of various genes during reproductive development and maturation in $P$. monodon, we previously constructed a cDNA microarray, ReproArray ${ }^{\text {GTS }}$, and carried out a high-throughput expression analysis of genes in ovary of wild $P$. monodon [24]. A second generation cDNA microarray was recently fabricated using 12 EST libraries from different tissues to cover as many and as diverse transcripts as possible. Expression levels of EST transcripts with gene ontology related to reproductive functions and those previously not reported in the NCBI EST penaeid shrimp database (unique genes) were investigated by using this new microarray to compare ovary and testis transcripts in both juvenile and broodstock shrimp (Figure 5). The expression levels from the microarray experiments were analyzed, as described in the Methods section, to obtain transcripts potentially relevant to testicular development.

Of 5,568 transcripts on the microarray, 2,133 transcripts were present in at least 8 of the 9 microarrays and had relative expression levels greater than the median value $\pm 1 \mathrm{SD}$ in at least one microarray (Figure $5 \mathrm{~A}$ ). Within this subset, 244 transcripts with higher abundance ( 3 fold) in ovary than testis and 239 transcripts with higher abundance ( 3 fold) in testis than ovary were identified (Figure 5B). From these differentially expressed genes, there were transcripts whose putative functions are possibly involved in testicular development (Figure 5C).

When examining the library sources of transcripts more abundantly expressed in ovaries, we found $51 \%$ were from the ovary, $22 \%$ from testis, $9 \%$ from hemocyte and heart each, $8 \%$ from gill, $1 \%$ from lymphoid organ and $<1 \%$ from the remaining tissues (Figure 5D). These transcripts included peritrophin (also called cortical rod protein, CRP), thrombospondin (TSP) and nuclear autoantigenic sperm protein (NASP). In the kuruma shrimp, $C R P$ and TSP are first scattered throughout the cytoplasm of oocytes and are subsequently localized in cortical rods during the cortical rod formation [25]. NASP is a histone-binding protein. Overexpression of NASP in mice testis affects progression of cell proliferation through the cell cycle [26,27]. Expression analysis of these genes $[20,28]$ and dolichyl diphosphooligocharide protein glycotransferase, asparagenyl tRNA synthetase and 
Table 1 Distribution of species that the testis ESTs were matched to known transcripts in the database using BlastX

\begin{tabular}{|c|c|c|c|c|c|c|}
\hline Common taxonomy & Phylum & $\begin{array}{l}\text { Frequency } \\
\text { (\#seq) }\end{array}$ & Percent & Species & Phylum & $\begin{array}{c}\text { Frequency } \\
\text { (\#seq) }\end{array}$ \\
\hline arthropods & Arthropoda & 753 & 65.6 & Tribolium castaneum & Arthropoda & 90 \\
\hline chordates & Chordata & 240 & 20.9 & Nasonia vitripennis & Arthropoda & 85 \\
\hline plants & Streptophyta & 45 & 3.9 & Apis mellifera & Arthropoda & 75 \\
\hline sea urchins & Echinodermata & 32 & 2.8 & Pediculus humanus & Arthropoda & 66 \\
\hline cnidarians & Cnidaria & 29 & 2.5 & Branchiostoma floridae & Chordata & 65 \\
\hline segmented worms & Annelida & 7 & 0.6 & Ixodes scapularis & Arthropoda & 56 \\
\hline molluscs & Mollusca & 5 & 0.4 & Penaeus monodon & Arthropoda & 55 \\
\hline nematodes & Nematoda & 4 & 0.3 & Triticum aestivum & Streptophyta & 38 \\
\hline placozoans & Placozoa & 4 & 0.3 & Strongylocentrotus purpuratus & Echinodermata & 30 \\
\hline apicomplexans & Apicomplexa & 4 & 0.3 & Acyrthosiphon pisum & Arthropoda & 29 \\
\hline ascomycetes & Ascomycota & 2 & 0.2 & Anopheles gambiae & Arthropoda & 26 \\
\hline ribbon worms & Nemertea & 1 & 0.1 & Aedes aegypti & Arthropoda & 22 \\
\hline trichomonads & Trichomonadida & 1 & 0.1 & Danio rerio & Chordata & 21 \\
\hline kinetoplastids & Kinetoplastida & 1 & 0.1 & Marsupenaeus japonicas & Arthropoda & 21 \\
\hline others & & 19 & 1.7 & Nematostella vectensis & Chordata & 18 \\
\hline \multirow[t]{10}{*}{ Total } & & 1,147 & & Litopenaeus vannamei & Arthropoda & 17 \\
\hline & & & & Xenopus laevis & Chordata & 17 \\
\hline & & & & Culex quinquefasciatus & Arthropoda & 16 \\
\hline & & & & Gallus gallus & Chordata & 16 \\
\hline & & & & Lepeophtheirus salmonis & Arthropoda & 13 \\
\hline & & & & Salmo salar & Chordata & 12 \\
\hline & & & & Ornithorhynchus anatinus & Chordata & 11 \\
\hline & & & & Hydra magnipapillata & Cnidaria & 10 \\
\hline & & & & others & & 338 \\
\hline & & & & Total & & 1,147 \\
\hline
\end{tabular}

3-oxoacid CoA transferase by semiquantitative RT-PCR (S. Klinbunga, unpublished data) revealed greater expression levels in ovary than testis of wild P. monodon broodstock. This validated the accuracy of the microarray analysis for gene expression analysis in P. monodon.

Transcripts with higher expression in testis were found mainly from the testis EST library (65\%), 8\% from heart, $7 \%$ from hemocyte, $5 \%$ from gill, $3 \%$ from ovary, $2 \%$ from hepatopancreas, $1 \%$ from intestine, and $1.5 \%$ from the rest (Figure 5E). Examples of these transcripts include argonaute 1, dynactin 5, and orphan 2. Argonaute proteins are key mediators for RNA silencing mechanisms [29]. Cytoplasmic dynactin forms a complex with dynein and plays a functional role in spermatid growth in Drosophila [30].

Based on the distribution of library sources where the differentially expressed transcripts came from, it is evident that we can obtain additional information by including cDNA probes from various EST libraries beyond testis and ovary libraries. This more comprehensive coverage of microarray probes demonstrates the usefulness of the present microarray version in gene expression analysis of $P$. monodon.
Within the 1,076 cDNA spots from testis ESTs that were fabricated onto the present version of cDNA microarrays, there were 169 transcripts with greater abundance in testis than ovary. Of these transcripts saposin-related protein and Dmc1 were consistently more abundant in testis than in ovary for both juvenile and broodstock comparisons. Moreover, these genes have previously been reported to be relevant to male reproduction in other organisms.

In vertebrates, saposins are a group of four small glycoproteins (A, B, C, and D), derived from a common precursor protein called prosaposin, which is reported to activate glycosphingolipid hydrolysis [31]. Inactivation of prosaposin gene resulted in accumulation of lactosylceramide, glucosylceramid, digalactosyl ceramide, sulfactide, ceramide, and globotriaosylceramide in lysosomes. A prosaposin -/- mouse model demonstrated that the mice die at day 35-40 after birth due to neurological defects [32]. The disruption of the prosaposin gene resulted in a reduction in size and weight: $30 \%$ of the testis, $37 \%$ of the epididymis, $75 \%$ of the seminal vesicles, and $60 \%$ of the prostate glands. Moreover, the smaller testes from the mutant mice were associated 


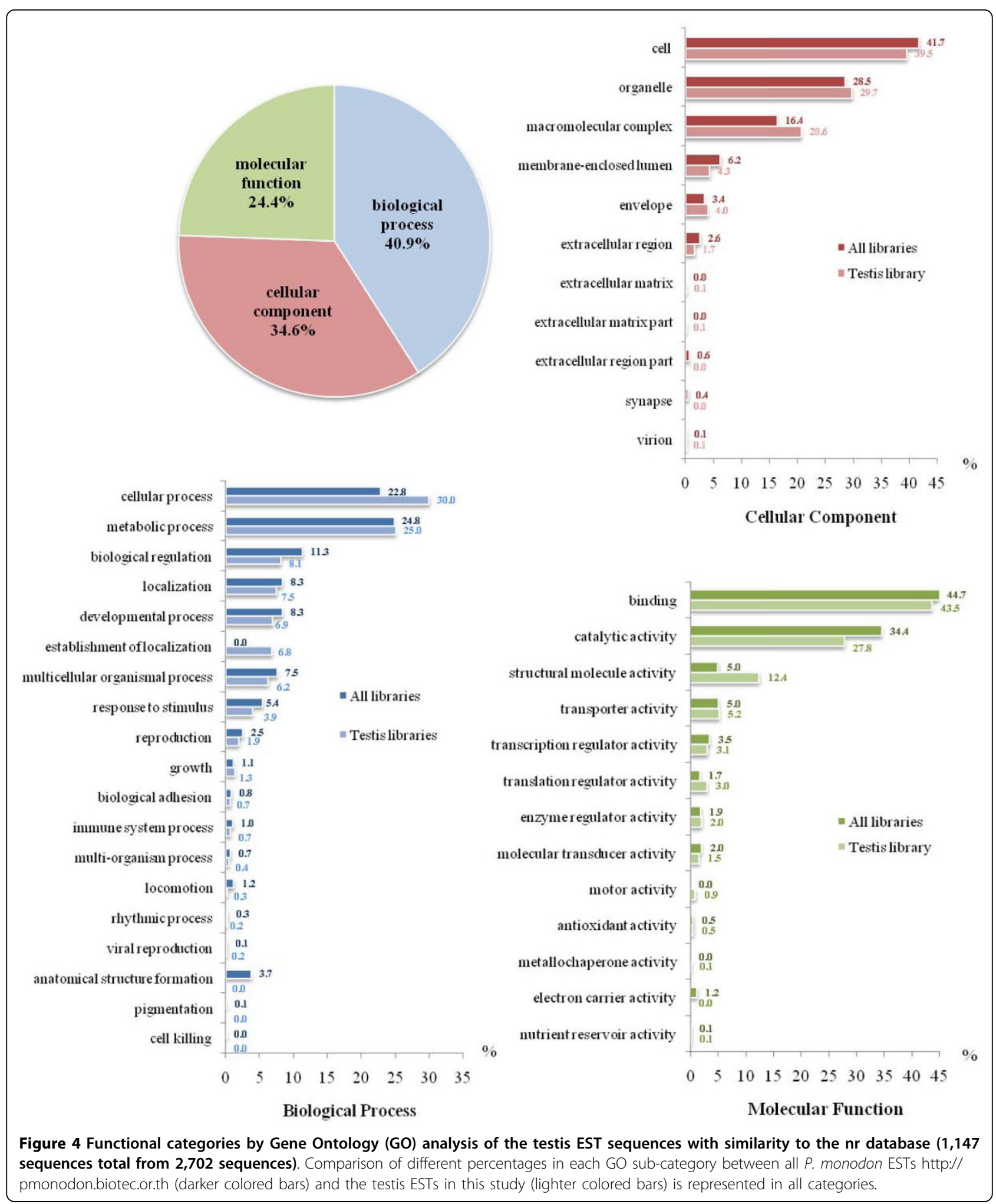




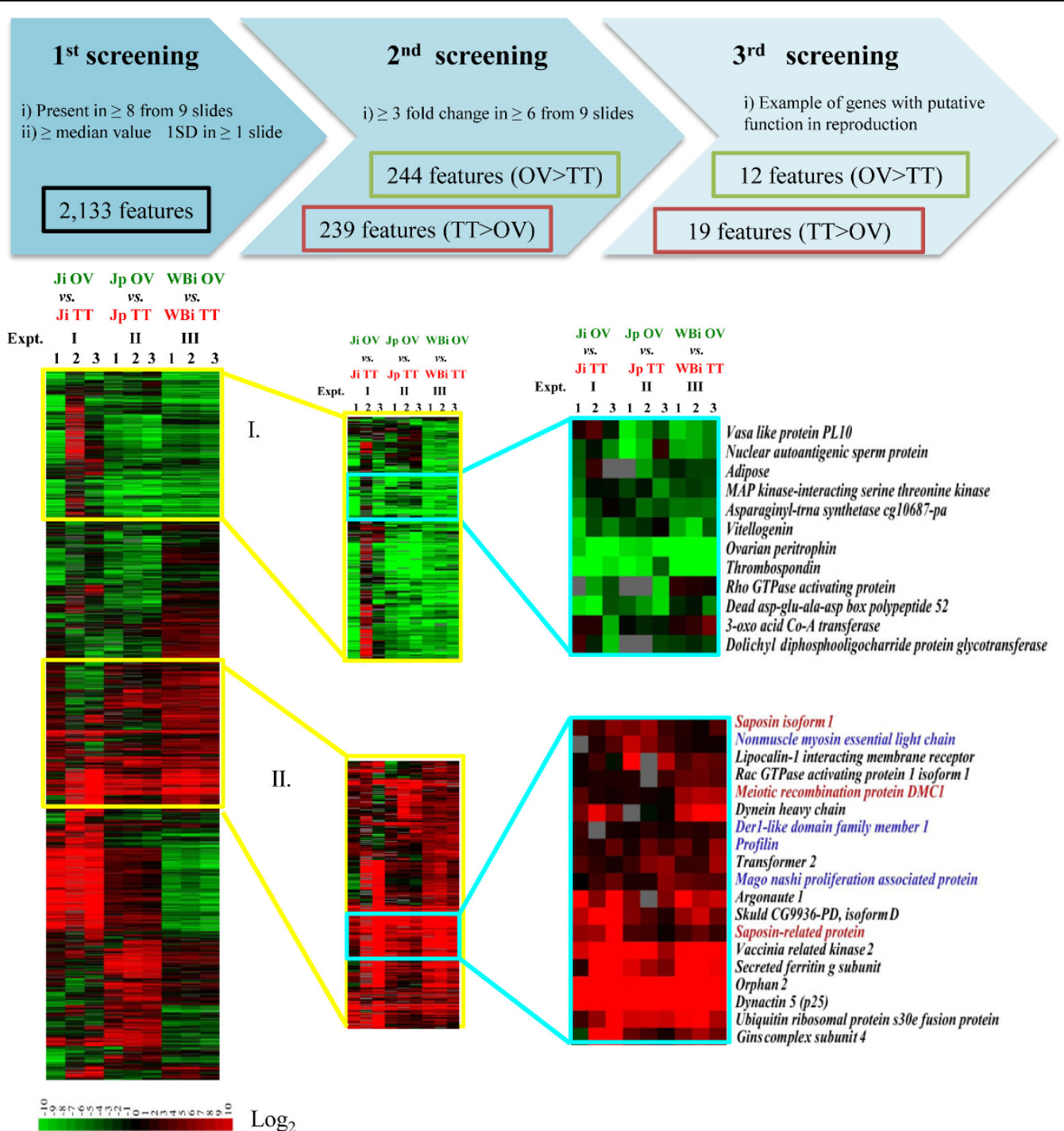

A.

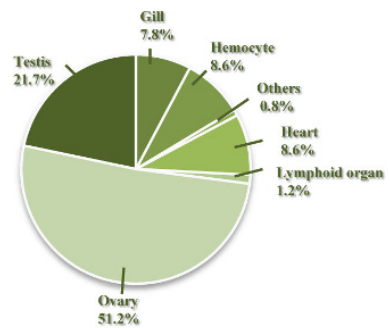

D.

B.

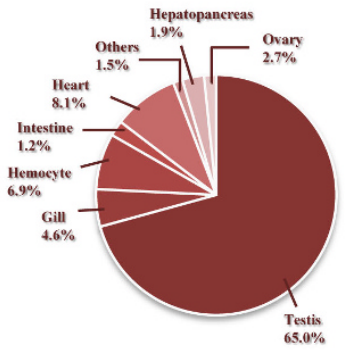

E.

Figure 5 Gene expression analysis by cDNA microarray comparing $P$. monodon transcripts between testis (TT) and ovary (OV) in individual juvenile (Ji), pooled juvenile (Jp) and individual wild-caught broodstock (WBi). TT was labeled with Cy5 fluorescent dye (red) and OV with Cy3 fluorescent dye (green). (A) Hierarchical clustering analysis of the transcripts present in at least 8 of 9 slides and whose expression differences were at least equal to median value \pm 1SD in at least 1 slide. (B) Clusters I and II of transcripts with higher expression levels in testis than ovary and vice versa with at least 3-fold difference in at least 6 of 9 slides. (C) Examples of differentially expressed transcripts with putative functions in reproductive development. Transcripts in blue letters are those which were not found in any EST libraries of other tissues. Saposin and Dmcl (in red) were further characterized by RACE-PCR. (D) Library distributions of transcripts expressed higher in ovary than in testis (244 transcripts) and (E) those expressed higher in testis than in ovary (239 transcripts). 
with reduced spermiogenesis, especially in the late spermatids [33].

Dmc1 (a RAC A-like recombinase) is known to be a specific factor for meiotic recombination and has been identified as a gene product specifically expressed during the early meiotic prophase [21]. Recently, the full-length Dmc1 cDNA was cloned from the testis of the Japanese eel (Anguilla japonica). Dmc1 mRNA was abundantly expressed in the testis and ovary with lower expressed in the brain. In situ hybridization revealed that Dmc1 of $A$. japonica was localized only in the primary spermatocytes implying its important role during the initial stages of spermatogenesis [34].

\section{Isolation and characterization of the full-length CDNA of saposin (PmSap) and Dmc1 (PmDmc1) in P. monodon}

Based on their differential expression levels seen in the microarray analysis and their possible involvement in testicular development from previous studies in other organisms, saposin-related protein (PmSap) and Dmc1 (PmDmc1) were further characterized by RACE-PCR to obtain their full-length cDNA sequences.

Full-length PmSap was found to be 3,034 bp in length containing an open reading frame (ORF) of 2,589 bp corresponding to a deduced protein of 862 amino acids with $5^{\prime}$ and $3^{\prime} \mathrm{UTR}$ s of 116 and $329 \mathrm{bp}$ (excluding the poly A tail), respectively (Figure 6A, accession number GU566728). This sequence significantly matched saposin isoform 1 of Tribolium castaneum $(E$-value $=1 \mathrm{e}-171)$. The expected molecular weight $(\mathrm{MW})$ and $\mathrm{p} I$ of the deduced Saposin were $95.63 \mathrm{kDa}$ and 4.65, respectively. Only one contig of saposin-related protein was previously found in ESTs from P. monodon.

Most saposins in vertebrate and invertebrate contain a signal peptide. Typically, vertebrate prosaposins contain two conserved SapA domains and four conserved SapB domains in which six equally placed cysteines are found in each SapB domain. In contrast, the numbers of saposin domains in invertebrates is less conserved. The absence of some of SapA domain produced variants of saposinrelated proteins in various taxa (Figure 6B). Moreover, there are variable numbers of SapB domains in invertebrates, from 6 domains present in the pea aphid, Acyrthosiphon pisum (Homoptera), to up to 9 domains in the black legged tick Ixodes scapularis (Acari) and Nasonia vitripennis (Hymenoptera) (Figure 6B). Additional SapB domains in invertebrate saposins may be explained by several rounds of tandem internal gene duplication as previously proposed for the creation of the four domain saposins in vertebrate [35].

In P. monodon, the deduced PmSap protein contained a signal peptide with a cleavage site between $\mathrm{Ala}_{21}$ and $\mathrm{Glu}_{22}$, two SapA and seven SapB domains (SapA: positions $25-58$ and $823-856$ with $E$-value $=2.74 \mathrm{e}-12$ and 1.56e-07, respectively; SapB: positions 68-144, 178-251, 272-346, 437-512, 531-606, 646-721, and 738-813 with $E$-value $=1.32 \mathrm{e}-22,5.32 \mathrm{e}-09,7.28 \mathrm{e}-16,4.34 \mathrm{e}-23,4.61 \mathrm{e}-27$, $2.63 \mathrm{e}-22$, and $5.83 \mathrm{e}-15$, respectively). Interestingly, six fixed positions of cysteine were found in each SapB domain of PmSap but conserved prolines in identical positions as previously reported in vertebrate saposins [31] were not found (data not shown). Five predicted glycosylation sites were found in SapB domains 1 (NET, positions 87-89), 3 (NTT, positions 291-293), 5 (NRT and NLS, positions 550-552 and 593-595, respectively) and 6 (NAT, positions 665-667). These predicted SapB domains significantly matched saposin-related protein A ( $E$-value $=8 \mathrm{e}-24 ;$ Uniprot No. Q9Y125), BmP109 $(E$-value $=7.4 \mathrm{e}-20 ;$ Uniprot No. O15997), Saposin $\mathrm{C}(E$-value $=6.4 \mathrm{e}-14 ;$ Uniprot No. P220097 $)$ and BmP109 $(E$-value $=3.4 \mathrm{e}-7$; Uniprot No. O15997), respectively.

The Dmc1 transcript which was only found in the testis cDNA library of $P$. monodon was further characterized. The full-length cDNA of PmDmc1 (accession number EU440762) was found to be 1,661 bp in length containing an ORF of 1,026 bp encoding a polypeptide of 341 amino acids. The highest similarity to this transcript was Dmc1 of Ixodes scapularis (E-value = 1e-147). The predicted $\mathrm{p} I$ and $\mathrm{MW}$ of the deduced Dmc1 were 5.35 and $37.54 \mathrm{kDa}$, respectively. The deduced Dmc1 protein contains an $\mathrm{HhH}$ motif (positions $46-75$, $E$-value $=2.73 \mathrm{e}-02$ ) and an AAA domain (positions $118-308, E$-value $=9.73 \mathrm{e}-06$, Figure 7A). The $\mathrm{HhH}$ motif is $\sim 20$ amino acid domain present in prokaryotic and eukaryotic non-sequence-specific DNA binding proteins involved in enzymatic activity. The gene products within the superfamily of AAA-ATPase are associated with diverse cellular activity. A bootstrapped neighborjoining tree reflects the relationships between the texa and the sparse representation of invertebrate sequence for the Dmc1 protein (Figure 7B).

\section{Expression of PmSap and PmDmc1 in testis of juveniles and domesticated and wild broodstock of $P$. monodon}

Tissue expression analysis is important for providing basic information needed to prioritize further analysis of functional genes. Based on the fact that a particular gene may be expressed in several tissues and possess different functions, rapid detection of PmSap and $P m D m c 1$ expression profiles in gonads of $P$. monodon by cDNA microarray was further confirmed by quantitative real-time PCR.

PmSap was more abundantly expressed in testis than ovary of $P$. monodon $(P<0.05$, Figure 8$)$. The expression levels of this transcript were not significantly different across different stages of either testis (WB-TT, DB- TT and J-TT) or ovary (WB- TT and J-TT). Dmc1 was less abundantly expressed in testis of domesticated 


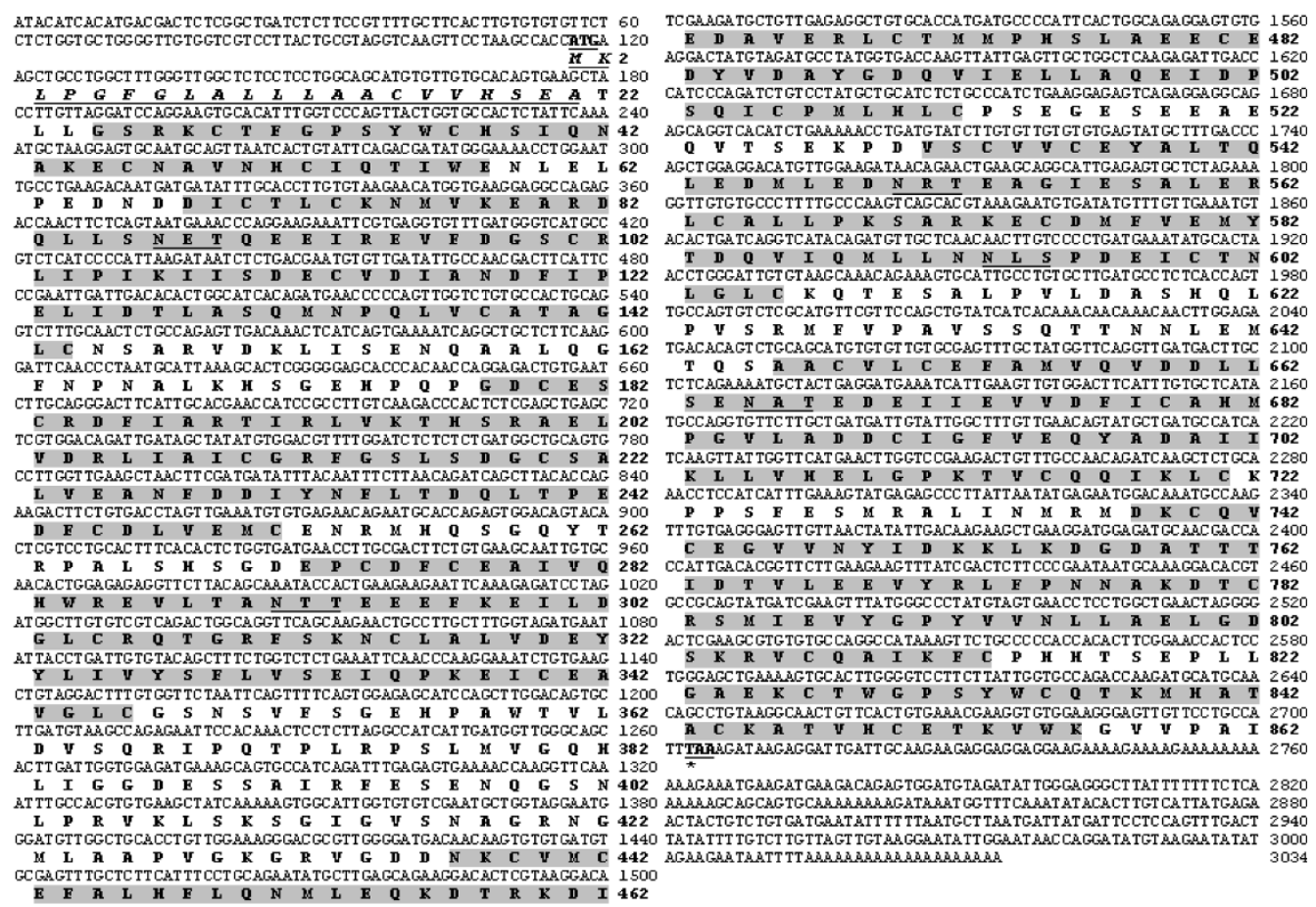

B

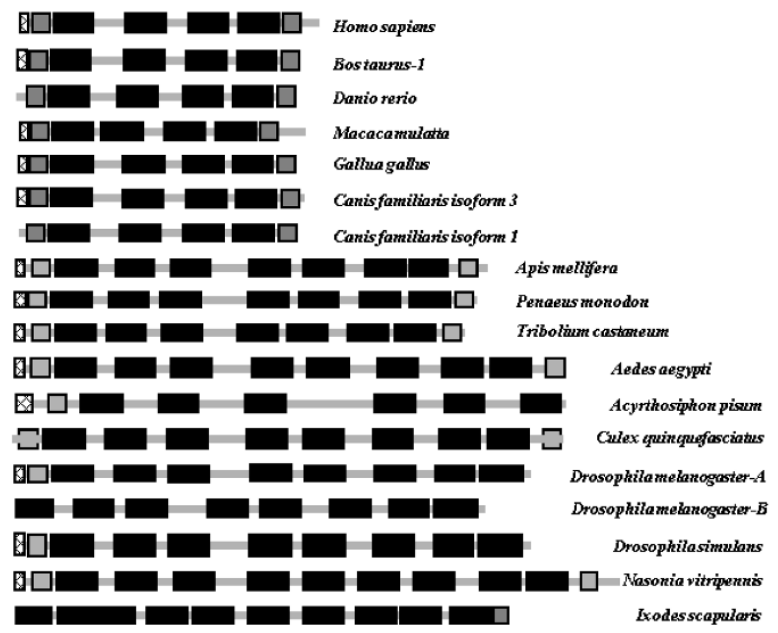

Signalpep tide $\square$ Sap A domain $\square$ Sap B domain

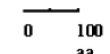

Figure 6 Analysis of Penaeus monodon Saposin (PmSap). (A) The full-length cDNA and deduced protein sequence of PmSap (3034 bp; ORF $2589 \mathrm{bp}, 862 \mathrm{aa}$ ) of $P$. monodon. Start (ATG) and stop (TAA) codons are illustrated in boldface and underlined. The signal peptide of the deduced PmSap protein is italicized and underlined. Putative N-linked glycosylation sites are underlined. Two domains of Saposin A (positions 25-58 and 823-856) and seven domains Saposin B (positions 68-144, 178-251, 272-346, 437-512, 531-606, 646-721, and 738-813 of the deduced protein) are highlighted. (B) Diagram showing SapA and SapB domains in prosaposin in various vertebrates; Homo sapiens (CAl40836), Bos taurus (NP_776586), Macaca mulatta (XP_001106592), Canis familiaris (XP_536382 and XP_861441), Gallus gallus (NP_990142), Danio rerio (AAH63994) and saposin-related protein in invertebrates; Acyrthosiphon pisum (XP_001943244), Apis mellifera (XP_392338), Tribolium castaneum (XP_966852), Aedes aegypti (XP_001662994), Culex quinquefasciatus (XP_001864689), Drosophila melanogaster (NP_524597 and NP_733408), Drosophila simulans (XP_002105562), Nasonia vitripennis (XP_001603446) and Ixodes scapularis (XP_002412058). Sequenced were retrieved from the GenBank and compared with saposin-related protein of $P$. monodon. Four SapB domains are conserved in vertebrate saposins whereas the number of SapB domains varies among invertebrate taxa. 
A

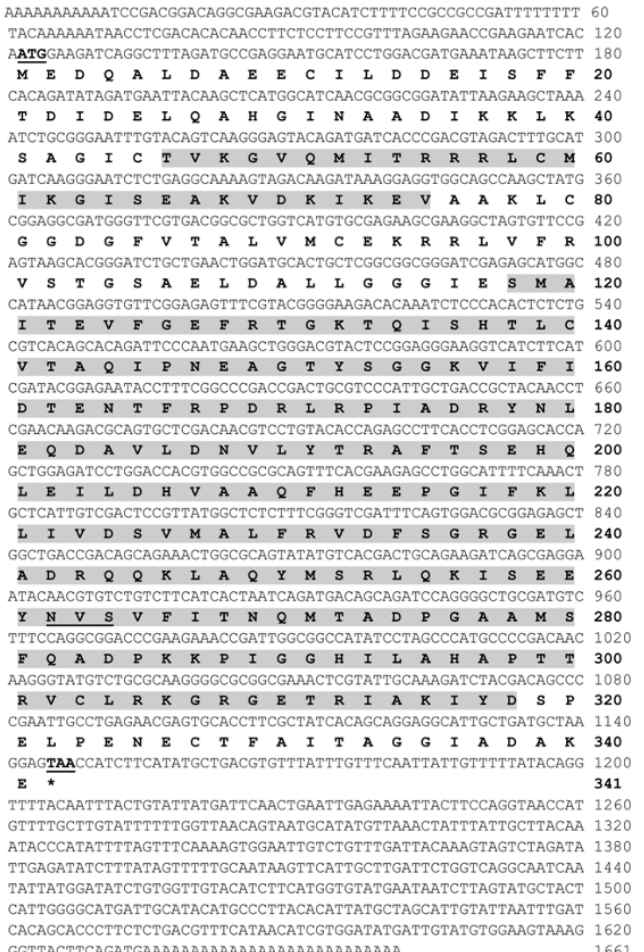
GGTTACTTCAGATGAAAAAAAAAAAAAAAAAAAAAAAAAAAAA
B

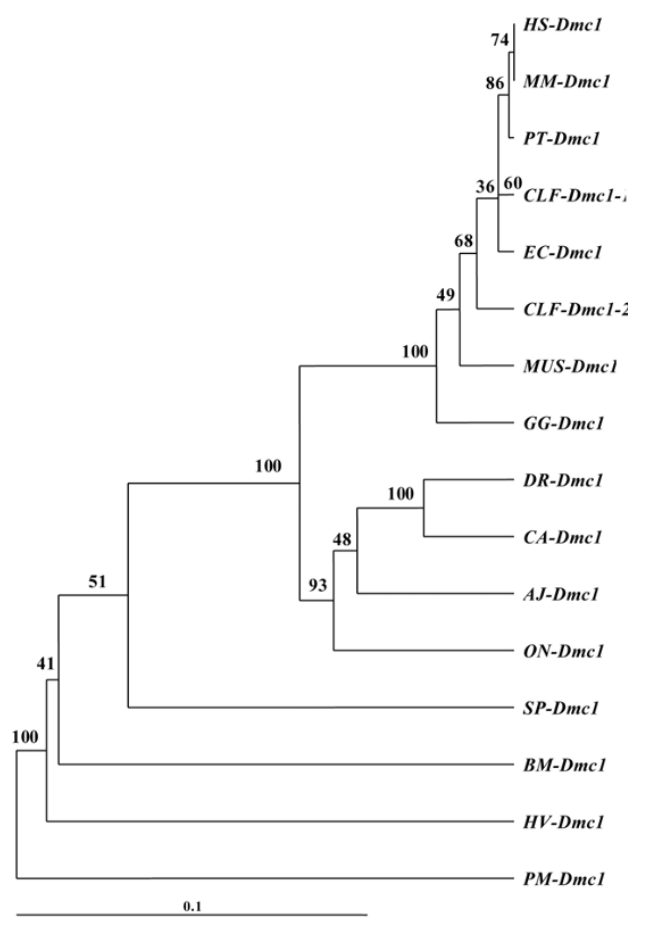

Figure 7 Analysis of Penaeus monodon Dmc1 (PmDmc1). (A) The full-length CDNA and deduced protein sequences of Dmc1 (1,661 bp; ORF $1,026 \mathrm{bp}, 341 \mathrm{aa}$ ) of $P$. monodon. Start (ATG) and stop (TAA) codons are illustrated in boldface and underlined. The deduced DMC1 protein contains an $\mathrm{HhH}$ domain (positions 46-75, E-value = 2.7e-02; highlighted)) and an AAA domain (positions 118-308, E-value = 9.73e-06; highlighted). (B) A bootstrapped neighbor-joining tree illustrating phylogentic relationships of Dmcl of various taxa. Values at the node represent the percentage of times that the particular node occurred in 1000 trees generated by bootstrapping the original aligned protein sequences. Protein sequences of different isoforms of Dmc1 from Homo sapiens (HS-Dmc1, NM_007068), Equus caballus (EC-Dmc1, XM_001501584), Macaca mulatta (MM-Dmc1, XM_001094012), Pan troglodytes (PT-Dmc1, XM_515130), Canis lupus familiaris (CLF-Dmc1-1, XM_844891 and CLF-Dmc1-2, XM_855217), Gallus gallus (GG-Dmc1, XM_425477), Mus musculus (MM-Dmc1, NM_010059), Anguilla japonica (AJ-Dmc1, AB182645), Oreochromis niloticus (ON-Dmc1, AB182646), Danio rerio (DR-Dmc1, NM_001020782), Carassius auratus (CA-Dmc1, EF545136), Bombyx mori (BM-Dmc1, NM_001044087), Hydra vulgaris (HV-DmC1, AB047581) and Strongylocentrotus purpuratus (SP-DmC1, XM_786187), were retrieved from GenBank and compared with Dmcl of $P$. monodon (PmDmc1).

broodstock than in wild broodstock and cultivated juvenile $P$. monodon males $(P<0.05$, Figure 8$)$. The expression level of this gene was also higher in testis than ovary $(P<0.05)$. Therefore, PmSap and PmDmc1 should play an important role in spermatogenesis (and testicular development) rather than oogenesis (and ovarian development) of $P$. monodon. Importantly, lower expression levels of PmDmc1 in domesticated versus wild broodstock suggest transcriptional levels of this gene may be used to indicate possible reduced maturation of reproduction in domesticated $P$. monodon.

Molecular mechanisms and expression patterns of genes controlling different steps of sperm maturation and testicular development should be examined for a better understanding of $P$. monodon reproductive maturation in captivity. The limited number of known genes expressed in testis of this economically important species was partially resolved by EST analysis in the present study. Typically, molecular studies of the hormonal and environmental effectors involving shrimp reproduction have been limited to one or a few genes. Here, we illustrate that cDNA microarrays are relatively simple, reliable and cost-effective for examining integrated interactions among genes in gonads of P. monodon. This method can help accelerate studies on reproductive development and maturation of P. monodon.

\section{Methods \\ EST Libraries}

The testis cDNA library of $P$. monodon was previously constructed as described in [5]. The lambda library was converted to the pBluescript library by in vivo excision. Colony PCR was performed in a $25 \mu \mathrm{l}$ reaction mixture containing $10 \mathrm{mM}$ Tris- $\mathrm{HCl}, \mathrm{pH} 8.3,50 \mathrm{mM} \mathrm{KCl}$, Enhancer solution, $200 \mathrm{mM}$ of each dNTP, $2 \mathrm{mM} \mathrm{MgCl}_{2}$, 

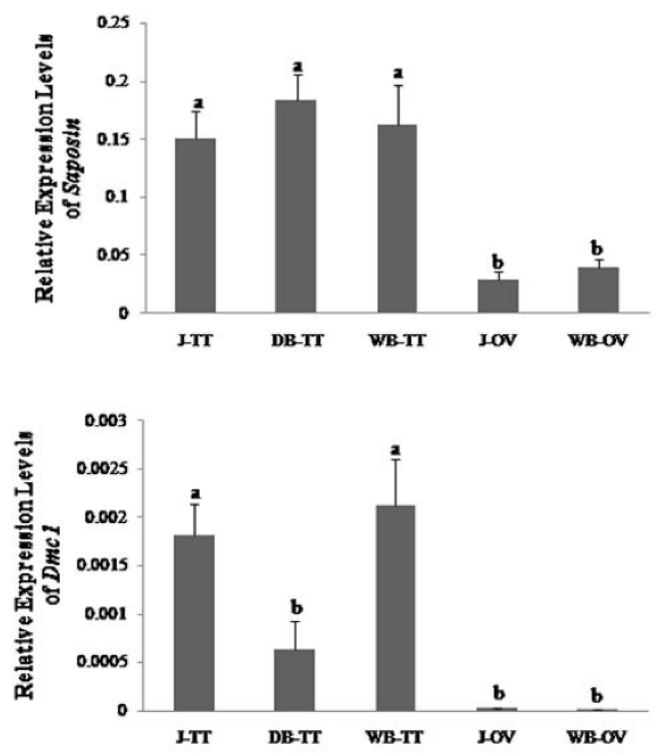

Figure 8 Real-time PCR analysis illustrating the relative expression levels of saposin in testis (TT) and ovary (OV) of $P$. monodon juvenile $(\mathrm{J})$, domesticated (DB) and wild broodstock (WB). Bars labeled with the same letters do not have significantly different expression levels $(P>0.05)$. J-TT $(N=5)$, DB-TT $(N=5)$, and WB-TT $(N=5)$ are testis of juveniles, domesticated broodstock, and wild broodstock, respectively. J-OV $(N=4)$ and WB-OV $(N=4)$ are ovary of juvenile and wild broodstock, respectively.

$0.2 \mu \mathrm{M}$ each of M13-F (5'-ACG TTG TAA AAC GAC GGC CAG-3') and M13-R (5'-ACA GGA AAC AGC TAT GAC CAT G-3'), and 1.25 unit of $i$-Taq ${ }^{\text {Tm}}$ DNA Polymerase (iNtRON Biotechnology). PCR was carried out in a thermocycler consisting of predenaturation at $94^{\circ} \mathrm{C}$ for $5 \mathrm{~min}$ followed by 35 cycles of denaturation at $94^{\circ} \mathrm{C}$ for $30 \mathrm{~s}$, annealing at $58^{\circ} \mathrm{C}$ for $1 \mathrm{~min}$ and extension at $72^{\circ} \mathrm{C}$ for 3 $\min$. The final extension was carried out at the same temperature for $7 \mathrm{~min}$. The colony PCR products were size-fractionated on $1.5 \%$ agarose gel and visualized after ethidium bromide staining. Clones with $>400$ bp inserts were selected for further sequencing. Plasmid was extracted using 96-well plate format (EZ-10 96-well spin column, Bio Basic). The concentrations of plasmids were measured using a NanoDrop 8000 . Nucleotide sequence of each clone was obtained using an automated DNA sequencer. The 4,803 sequences of the testis ESTs from this study were deposited in NCBI dbEST http://www. ncbi.nlm.nih.gov/dbEST/ with accession numbers of GW992816-GW996323, HO000142-HO000184, GE613296 - GE614547.

\section{In silico analysis of ESTs}

Nucleotide sequences were analyzed using ESTplus, an integrative system for comprehensive and customized EST analysis and proteomic data matching [6], as summarized in Figure 1. Briefly, the sequencing data were analyzed by SeqClean (removal of the polyA/polyT tail, low-quality ends, short sequences and those containing cloning vector), RepeatMasker (masking of the sequences when matched with sequences in the largest repeat library, the RepBase, that covers a number of organisms including human, rodent, zebrafish, Drosophila, and Arabidopsis thaliana) (University of Washington Genome Center, Seattle; http://ftp.genome.washington.edu/cgi-bin/RepeatMasker), and CAP3 (assembly and clustering of EST sequences) [36]. The post-processed sequences were further annotated for biological activities by comparison with the NCBI nr database using BlastN (a nucleotidelevel annotation, $E$-value $<10^{-5}$ ), BlastX (a protein-level annotation, $E$-value $<10^{-5}$ ), BLAST2GO (Gene Ontology prediction of the annotated proteins from BlastX program), and InterProScan (protein signature identification).

To identify ESTs found only in the testis cDNA library of $P$. monodon, all newly sequenced contigs and singletons were compared against all sequences (38,429 ESTs) from the P. monodon database (PmDB: http://pmonodon.biotec.or.th). Moreover, to identify novel transcripts that have not been previously reported in shrimp, the sequenced data were also compared against all available Penaeidae ESTs (207,852 ESTs) from NCBI http://ncbi. nlm.nih.gov retrieved on 01/11/09.

\section{Microarray analysis for identification of differential expression transcripts in testis of $P$. monodon}

A cDNA microarray was constructed from various EST libraries of $P$. monodon, consisting of 5,568 features (1,076 unique cDNA features were amplified from testis EST libraries). The arrays were post-processed according to [24] immediately before hybridization.

Total RNA was extracted from testis and ovary of juveniles (4 month-old) and broodstock originating from the Andaman Sea (west of peninsular Thailand). Contaminating genomic DNA was removed by treatment with DNase I ( $0.15 \mathrm{U} / \mu \mathrm{g}$ total RNA) at $37^{\circ} \mathrm{C}$ for $30 \mathrm{~min}$. The first-strand cDNA was synthesized and fluorescently labeled according to [24]. RNA from ovary was labeled with $\mathrm{Cy} 3$ dye as a reference and RNA from testis was labeled with Cy5 dye. The Cy3- and Cy5-samples were mixed together and hybridized onto the arrays overnight. The hybridized slides were washed according to Corning's instruction. Nine microarray experiments were performed and the details of comparison between gene expression profiles of ovaries and testes are summarized in Table 2.

\section{Microarray imaging and data analysis}

The hybridized slides were scanned with a GenePix 4000B (Molecular Devices, Sunnyvale, CA) and processed using GenePix Pro version 6.1. Only spots with 
Table 2 Summary of microarray experiments in this study

\begin{tabular}{lll}
\hline Experiment & $\begin{array}{l}\text { Female } \\
\text { Green (Cy3) }\end{array}$ & $\begin{array}{l}\text { Male } \\
\text { Red (Cy5) }\end{array}$ \\
\hline I. Comparison of gene expression levels between ovary and testis in individual juveniles \\
1 & Ovary from juvenile 1 & \\
2 & Ovary from juvenile 2 & Testis from juvenile 1 \\
3 & Ovary from juvenile 3 & Testis from juvenile 2 \\
II. Comparison of gene expression levels between ovaries and testes pooled from juveniles & Testis from juvenile 3 \\
1 & Pooled ovaries from juveniles $(n=98)$ & Pooled testes from juveniles ( $(n=114)$ \\
2 & Pooled ovaries from juveniles $(n=98)$ & Pooled testes from juveniles $(n=114)$ \\
3 & Pooled ovaries from juveniles $(n=98)$ & Pooled testes from juveniles $(n=114)$ \\
III. Comparison of gene expression levels between ovaries and testes pooled from broodstock & \\
1 & Ovary from broodstock 1 (GSI*: 12.4) & Testis from broodstock 1 (GSI: 1.1) \\
2 & Ovary from broodstock 2 (GSI: 11.2) & Testis from broodstock 2 (GSI: 1.1) \\
3 & Ovary from broodstock 3 (GSI: 12.6) & Testis from broodstock 3 (GSI: 1.1) \\
\hline
\end{tabular}

*Gonadosomatic Index (GSI) = \% gonad weight/body weight

intensities greater than one standard deviation above the background intensity were further analyzed. The processed data were normalized within each array by the scaled print-tip (Lowess) method, and across arrays, using the Aroma package [37], (available from http:// www.maths.lth.se/help/R/aroma/, run in R project environment http://cran.r-project.org. The microarray data have been deposited in NCBIs Gene Expression Omnibus http://www.ncbi.nlm.nih.gov/geo/ with GEO accession number GSE19037 at [38]. The average logarithmic base 2 values of relative intensities between Cy3- and Cy5- samples ( $M$ values) were subjected to hierarchical clustering analysis and illustrated using the Treeview software [39]. To identify differential expressed transcripts, only transcripts with relative expression level changes more than the median value \pm SD in at least 1 array and present in at least 8 of the 9 arrays were further considered. A 3-fold change in at least 6 of the 9 arrays was considered as criteria for differential expression.

\section{Examination of full-length cDNA sequences of Saposin and Dmc1 by Rapid Amplification of cDNA Ends- Polymerase Chain Reaction (RACE-PCR)}

Gene-specific primers for RACE-PCR of P. monodon Saposin and Dmc1 were designed (Table 3). RACEPCRs of Saposin and Dmc1 were carried out using a BD SMART RACE cDNA Amplification Kit following the protocol recommended by the manufacturer (BD Biosciences Clontech). The amplified fragment of each gene was electrophoretically analyzed and eluted from an agarose gel before cloning into pGEM-T Easy vector (Promega) and sequencing [40]. The full-length cDNA was assembled from EST and RACE-PCR products
Table 3 Primer sequence, melting temperature and the expected amplification product of PmSap and PmDmc1

\begin{tabular}{lllc}
\hline Gene/Primer & Sequence & $\begin{array}{l}\text { Tm } \\
\left({ }^{\circ} \mathbf{C}\right)\end{array}$ & $\begin{array}{l}\text { Size } \\
(\mathbf{b p})\end{array}$ \\
\hline $\begin{array}{l}\text { RACE-PCR } \\
\text { Saposin }\end{array}$ & & & \\
5'-RACE-1 & $5^{\prime}$ - & 86 & - \\
& CTGGCACCAATAAGAAGGACCCCAAGTG- & & \\
& $3^{\prime}$ & & \\
5'-RACE-2 & 5'- & 86 & - \\
& CAGATGGGCAGAGATGCAGCATAGGACA- & & \\
& 3' & & \\
Dmc1 & & & \\
5'-RACE & 5'-GCCGCCAATCGGTTCTTCGGGTCC-3' & 82 & - \\
3'-RACE & 5'-CCTTCGCTATCACAGCAGGAGGCATTG- & 84 & - \\
& 3' & & \\
\hline
\end{tabular}

\section{Real-time}

PCR

Saposin

Standard F: 5'-GCTATGGTTCAGGTTGATGACTTGC-3' 74

curve

R: 5'-ACTCCCTTCCACACCTTCGTTTC-3' 70

Real-time PCR F: 5'-CCATAAAGTTCTGCCCCCACCAC-3' 68

R: 5'-CCCTTCCACACCTTCGTTCACA-3' 70

$E F-1 \alpha$

Standard F: 5'-GCTCTTACCGAGGCTGTCCC-3' 66

434

curve

R: 5'-GTGGGTGTAATCAAGGAGGTCAA-3' 68

Real-time PCR F: 5'-TTCCGACTCCAAGAACGACC-3' 62

R: 5'-GAGCAGTGTGGCAATCAAGC-3' 62

Dmc1

Standard F: 5'-ATGGAAGATCAGGCTTTAGATGC-3' $66 \quad 425$

curve

R: 5'-GTGACGCAGAGAGTGTGGGAG-3' 68

Real-time PCR F: 5'-ATGTGCGAGAAGCGAAGGC-3' 60

150 
(hereafter called PmSap and PmDmc1). The sequences of PmSap and PmDmc1 were deposited with accession numbers of GU566728 and EU440762, respectively. The functional domains of the deduced amino acids of these genes were analyzed using SMART http://smart.emblheidelberg.de/. The $\mathrm{p} I$ and molecular weight were estimated using ProtParam http://www.expasy.org/tools/ protparam.html.

\section{Gene expression analysis of PmSap and PmDmc1 by quantitative real-time PCR}

Gene-specific primers were designed for PmSap, PmDmc1 and Elongation factor 1 alpha (EF-1 $\alpha$, Table $3)$. For construction of the standard curve of each transcript, a plasmid containing the transcript was constructed by cloning PCR product into pGEM-Teasy vector and transforming the resulting vector into $E$. coli JM109. The plasmid was extracted and used as the template for construction of the standard curve by 10-fold serial dilutions $\left(10^{3}-10^{9}\right.$ copy numbers). Real-time PCR reactions were carried out in a 96-well plate in triplicate.

The expression levels of PmSap and PmDmc1 in testis from juvenile (J-TT, $N=5$ ), domesticated broodstock (DB-TT, $N=5$ ), and wild broodstock (WB-TT, $N=5$ ) and ovary from juvenile (J-OV, $N=4)$ and wild broodstock (WB-OV, $N=4$ ) were further analyzed by quantitative real-time PCR analysis. $E F-1 \alpha$ was used as an internal control. Each primer set was designed to generate 120 to $150 \mathrm{bp}$ amplicons (Table 3). Each reaction was performed in a $15 \mu \mathrm{l}$ reaction volume containing $2 \times$ LightCycler 480 SYBR Green I Master (Roche), 50 ng of first strand cDNA template, and $0.2 \mu \mathrm{M}$ or $0.4 \mu \mathrm{M}$ of each primer pair. Cycling parameters were $95^{\circ} \mathrm{C}$ for 10 min, 40 cycles of $95^{\circ} \mathrm{C}$ for $15 \mathrm{sec}, 58^{\circ} \mathrm{C}$ for $30 \mathrm{sec}$, and $72^{\circ} \mathrm{C}$ for $30 \mathrm{sec}$. The specificity of PCR products was confirmed by melting curve analysis by heating at $95^{\circ} \mathrm{C}$ for $15 \mathrm{sec}, 65^{\circ} \mathrm{C}$ for $1 \mathrm{~min}$ before heating to $97^{\circ} \mathrm{C}$ and gradually cooling down to $40^{\circ} \mathrm{C}$ within $10 \mathrm{sec}$. Real-time PCR of each shrimp was tested in duplicate. Relative expression levels (copy number of the target gene/that of $E F-1 \alpha)$ of different sample groups were statistically tested by ANOVA followed by Duncan's new multiple range test or Tukey test $(P<0.05)$.

\footnotetext{
Acknowledgements

This research is supported by the National Center for Genetic Engineering and Biotechnology (BIOTEC). Part of this research (library construction, RACE$P C R$ and real-time-PCR) was carried out by RL during the PhD program and supported by the Royal Golden Jubilee PhD program, the Thailand Research Funds (TRF), Thailand. We would like to thank Dr. Amy Lum for reading and improving the manuscript. Also, we would like to thank Prof. Morakot Tanticharoen for her mentorship of this research program.

\section{Author details}

${ }^{1}$ National Center for Genetic Engineering and Biotechnology (BIOTEC), National Science and Technology Development Agency, Klong 1, Klong
}

Luang, Pathumthani 12120, Thailand. ${ }^{2}$ Program in Biotechnology, Faculty of Science, Chulalongkorn University, Bangkok 10330, Thailand. ${ }^{3}$ Center of Excellence for Marine Biotechnology, Faculty of Science, Chulalongkorn University, Bangkok 10330, Thailand. ${ }^{4}$ Department of Marine Science, Faculty of Science, Chulalongkorn University, Bangkok 10330, Thailand.

\section{Authors' contributions}

RL and SK constructed the testes EST library. TW, RL and NT carried out plasmid isolation and sequencing. TW performed in silico analysis of CDNA sequences. UU, TW and NK constructed CDNA microarray chips and performed microarray experiments. RL carried out gene expression analysis experiments and full-length characterization. PM, NK and SK conceived the work. TW, RL, NK and SK wrote the manuscript. All authors read and approved this manuscript.

Received: 26 January 2010 Accepted: 9 August 2010

Published: 9 August 2010

\section{References}

1. Rosenberry B: World Shrimp Farming. San Diego, CA: Shrimp News international 2000.

2. Browdy CL: A review of the reproductive biology of penaeus species: perspectives on controlled shrimp maturation systems for high quality nauplii production. Proceedings of the Special Session on Shrimp Farming, World Aquaculture Society Baton Rouge, LA, USAWyban J 1992, 22-51.

3. Withyachumnarnkul B, Boonsaeng V, Flegel TW, Panyim S, Wongteerasupaya C: Domestication and selective breeding of Penaeus monodon in Thailand. Proceedings to the Special Session on Advances in Shrimp Biotechnology, The Fifth Asian Fisheries Forum: International Conference on Fisheries and Food Security Beyond the Year: 11-14 November 1998; Chiangmai, Thailand Flegel TW 2000, 73-77.

4. Leelatanawit R, Klinbunga S, Aoki T, Hirono I, Valyasevi R, Menasveta P: Suppression subtractive hybridization (SSH) for isolation and characterization of genes related to testicular development of the giant tiger shrimp Penaeus monodon. BMB Reports 2008, 41(11):796-802.

5. Leelatanawit R, Sittikankeaw K, Yocawibun P, Klinbunga S, Roytrakul S, Aoki T, Hirono I, Menasveta P: Identification, characterization and expression of sex-related genes in testes of the giant tiger shrimp Penaeus monodon. Comp Biochem Physiol A 2009, 152:66-76.

6. Pacharawongsakda E, Yokwai S, Karoonuthaisiri N, Wichadakul D, Ingsriswang S: ESTplus: an integrative system for comprehensive and customized EST analysis and proteomic data matching. Proceedings of the 2nd International Conference on Bioinformatics and Biomedical Engineering (iCBBE2008): 16-18 May 2008; Shanghai, China 2008, 29-32.

7. The Tribolium Genome Sequencing Consortium: The genome of the model beetle and pest Tribolium castenuem. Nature 2008, 452:946-955

8. Shit S, Atreja SK: Phospholipase A2 activation by hydrogen peroxide during in vitro capacitation of buffalo spermatozoa. Indian J Exp Biol 2004, 42(5):486-90.

9. Pietrobon EO, Soria M, Domínguez LÁ, De Los Ángeles Monclus M, Fornés MW: Simultaneous activation of PLA2 and PLC are required to promote acrosomal reaction stimulated by progesterone via G-proteins. Mol Reprod Dev 2005, 70:58-63.

10. Newmark PA, Boswell RE: The mago nashi locus encodes an essential product required for germ plasm assembly in Drosophila. Development 1994, 120:1303-1313.

11. Verheyen EM, Colley L: Profilin mutations disrupt multiple actindependent processes during Drosophila development. Development 1994, 120:717-728.

12. Witke W, Sutherland JD, Sharpe A, Arai M, Kwiatkowski DJ: Profilin I is essential for cell survival and cell division in early mouse development. Proc Natl Acad Sci USA 2001, 98(7):3832.

13. Ono $S$, Minami $N$, Abe $H$, Obinata $T$ : Characterization of novel A cofilin isoform that is predominantly expressed in mammalian skeletal muscle. J Biol Chem 1994, 269:15280-15286.

14. Cottrelle P, Thiele D, Price VL, Memet S, Micouin J-Y, Marck C, Buhler J-M, Sentenac A, Fromageot P: Cloning, nucleotide sequence, and expression of one of two genes coding for yeast elongation factor $1 \alpha$. J Biol Chem 1985, 260:3090-3096.

15. Dalla Pavera R, Gelmann EP, Martionotti S, Franchini G, Papa TS, Gallo RC, Wong-Staal F: Cloning and characterization of different human 
sequences related to the one gene ( $\mathrm{v}$-myc) of avian myelocytomatosis virus (MC-29). Proc Natl Acad Sci USA 1982, 79:6497-6501

16. Heerdt BG, Halsey HK, Lipkin M, Augenlicht LH: Expression of mitochondrial cytochrome $\mathrm{c}$ oxidase in human colonie cell differentiation, transformation, and risk for colonic cancer. Cancer Res 1990, 50:1596-1600.

17. Pines J, Hunter T: p34 cdc2: the $S$ and M kinase? New Biol 1990, 2:389-401.

18. Naz RK, Ahmad K, Kaplan P: Involvement of cyclins and cdc2 serine/ threonine protein kinase in human sperm cell function. Biol Reprod 1993, 48:720-728.

19. Godet M, Damestoy A, Mouradian S, Rudkin BB, Durand P: Key role for cyclin-dependent kinases in the first and second meiotic divisions of rat spermatocytes. Biol Reprod 2004, 70:1147-1152.

20. Preechaphol R, Leelatanawit R, Sittikankeaw K, Klinbunga S, Khamnamtong B, Puanglarp N, Menasveta P: Expressed sequence tag analysis for identification and characterization of sex-related genes in the giant tiger shrimp Penaeus monodon. J Biochem Mol Biol 2007, 40:501-510.

21. Koshiyama A, Hamada FN, Namekawa SH, Iwabata K, Sugawara H, Sakamoto A, Ishizaki T, Sakaguchi K: Sumoylation of a meiosis-specific RecA homolog, Lim15/Dmc1, via interaction with the small ubiquitinrelated modifier (SUMO)-conjugating enzyme Ubc9. FEBS J 2006, 273:4003-4012.

22. Takahashi Y, Kikuchi Y: Yeast PIAS-type UII1/Siz1 is composed of SUMO ligase and regulatory domains. J Biol Chem 2005, 280:35822-35828.

23. Shen $B$, Zhang Z, Wang $Y$, Wang G, Chen $Y$, Lin P, Wang S, Zou Z: Differential expression of ubiquitin-conjugating enzyme E2r in the developing ovary and testis of penaeid shrimp Marsupenaeus japonicus. Mol Biol Rep 2008, 36:1149-1157.

24. Karoonuthaisiri N, Sittikankeaw K, Preechaphol R, Kalachikov S, Wongsurawat T, Uawisetwathana U, Russo JJ, Ju J, Klinbunga S, Kirtikara K: ReproArray ${ }^{\mathrm{GTS}}$ : A cDNA microarray for identification of reproductionrelated genes in the giant tiger shrimp Penaeus monodon and characterization of a novel nuclear autoantigenic sperm protein (NASP) gene. Comp Biochem Physiol D 2009, 4:90-99.

25. Okumura T, Kim YK, Kawazoe I, Yamano K, Tsutsui N, Aida K: Expression of vitellogenin and cortical rod proteins during induced ovarian development by eyestalk ablation in the kuruma prawn, Marsupenaeus japonicus. Comp Endrocrinol Physiol A 2006, 143:246-253.

26. Richardson RT, Batova IN, Zheng L-X, Whitfield M, Marzluff WF, O'Rand MG: Characterization of the histone $\mathrm{H} 1$ binding protein, NASP, as a cell cycle regulated, somatic protein. J Biol Chem 2000, 275:30378-30386.

27. Richardson RT, Alekseev OM, Grossman G, Widgren EE, Thresher R, Wagner EJ, Sullivan KD, Marzluff WF, O'Rand MG: Nuclear autoantigenic sperm protein (NASP), a linker histone chaperone that is required for cell proliferation. J Biol Chem 2006, 281:21526-21534.

28. Leelatanawit $R$, Klinbunga S, Puanglarp N, Tassanakajon A, Jarayabhand P Hirono I, Aoki T, Menasveta P: Isolation and characterization of differentially expressed genes in ovaries and testes of the giant tiger shrimp (Penaeus monodon). Mar Biotechnol 2004, 6:S506-S510.

29. Parker JS, Barford D: Argonaute: a scaffold for the function of short regulatory RNAs. TRENDS Biochem Sci 2006, 31:622-630.

30. Ghosh-Roy A, Kulkarni M, Kumar V, Shirolikar S, Ray K: Cytoplasmic dyneindynactin complex is required for spermatid growth but not axoneme assembly in Drosophila. Mol Biol Cell 2004, 15:2470-2483.

31. Kishimoto Y, Hiraiwa M, O'Brien JS: Saposins: structure, function, distribution, and molecular genetics. J Lipid Res 1992, 33:1255-1267.

32. Fujita N, Suzuki K, Vanier M, Popko B, Maeda N, Klein A, Henseler M, Sandhoff K, Nakayasu H, Suzuki K: Targeted disruption of the mouse sphingolipid activator gene: a comples phenotype, including severe leukodystrophy and wide-spread storage of multiple sphingolipids. Human Mol Gen 1996, 5:711-725.

33. Morales $C R$, Zhao $Q$, Lefrancois $S$, Ham D: Role of prosaposin in the male reproductive system: effect of prosaposin inactivation on the testes, epididymis, prostate, and seminal vesicles. Arch Androl 2000, 44(3):173-186.

34. Kajiura-Kobayashi $H$, Kobayashi T, Nagahama Y: Cloning of cDNAs and the differential expression of A-type cyclins and Dmc1 during spermatogenesis in the Japanese eel, a teleost fish. Dev Dynamics 2005, 232:1115-1123.
35. Hazkani-Covo E, Altman N, Horowitz M, Graur D: The Evolutionary History of Prosaposin: Two Successive Tandem-Duplication Events Gave Rise to the Four Saposin Domains in Vertebrates. J Mol Evol 2002, 54:30-34.

36. Huang $X$, Madan A: CAP3: A DNA sequence assembly program. Genome Res 1999, 868-877.

37. Bengtsson $\mathrm{H}$ : aroma - An R Object-oriented Microarray Analysis environment Preprints in Mathematical Sciences:18, Mathematical Statistics, Lund University 2004.

38. Edgar R, Domrachev M, Lash AE: Gene Expression Omnibus: NCBI gene expression and hybridization array data repository. Nucleic Acids Res 2002, 30:207-210.

39. Eisen MB, Spellman PT, Brown PO, Botstein D: Cluster analysis and display of genome-wide expression patterns. Proc Natl Acad Sci USA 1998, 95:14863-14868

40. Sambrook J, Russell DW: Molecular Cloning: A Laboratory Manual New York, USA; Cold Spring Harbor Laboratory Press, 32001.

doi:10.1186/1471-2199-11-55

Cite this article as: Wongsurawat et al: Identification of testis-relevant genes using in silico analysis from testis ESTs and CDNA microarray in the black tiger shrimp (Penaeus monodon). BMC Molecular Biology 2010 11:55.

\section{Submit your next manuscript to BioMed Central and take full advantage of:}

- Convenient online submission

- Thorough peer review

- No space constraints or color figure charges

- Immediate publication on acceptance

- Inclusion in PubMed, CAS, Scopus and Google Scholar

- Research which is freely available for redistribution 